\title{
Uso do fluralaner no tratamento da demodicidose canina juvenil generalizada: relato de caso
}

[Use of fluralaner on canine generalized juvenile demodicosis treatment: case report]

\author{
J.A.B. Bezerra, I.R.S. Cardoso, R.T.G.A. Rodrigues, K.D. Filgueira
}

Universidade Federal Rural do Semiárido - Ufersa - Mossoró, RN

\begin{abstract}
RESUMO
O objetivo do presente trabalho foi relatar a eficácia do fluralaner no tratamento da demodicidose juvenil generalizada canina. Dois caninos, apresentando dois e três meses de idade, com diagnóstico clínico e parasitológico de demodicidose generalizada, foram tratados com administração única de fluralaner, na dose recomendada em bula pelo fabricante. Além disso, foi realizada a terapia adjuvante à base de xampu de peróxido de benzoíla e domperidona. Observou-se uma resposta terapêutica satisfatória, com repilação completa ao $30^{\circ}$ dia após a administração do fármaco. Para cada paciente, foi realizado exame parasitológico do raspado cutâneo aos 75 e 90 dias seguintes ao início do tratamento, e todos foram negativos. Tendo em vista a elevada eficácia do tratamento proposto, sugere-se a inclusão do fluralaner nos protocolos terapêuticos destinados à demodicidose canina, particularmente nos pacientes pediátricos $\mathrm{e}$ com a forma generalizada da doença.
\end{abstract}

Palavras-chave: isoxazolina, Demodex canis, dermatologia

\begin{abstract}
The aim of the present study was to report the efficiency of fluralaner on the treatment of two cases of canine generalized juvenile demodicosis. Two puppies, aging two and three months old, with the clinic and parasitological diagnosis of generalized demodicosis were treated with single administration of fluralaner. according to the dose recommended by the responsible laboratory. Additionally, adjuvant therapy was applied using benzoyl peroxide shampoo and domperidone. A satisfactory therapeutic response was observed, and complete repilation was present at the 30th day after drug administration. For each patient, at the 75th and 90th day after the treatment began, skin scrapings were performed in order to investigate the presence of Demodex sp; and all were negative. Considering the high efficiency of the treatment used, we suggest the inclusion of fluralaner on the therapeutic protocol for canine demodicosis, particularly in pediatric patients and with the generalized form of the disease.
\end{abstract}

Keywords: isoxazoline; Demodex canis; dermatology

\section{INTRODUÇÃO}

A demodicidose é uma dermatopatia parasitária cujo principal agente etiológico equivale ao Demodex canis. Esse corresponde a um ácaro, integrante normal do microbioma cutâneo dos cães, albergando-se no interior dos folículos pilosos e nas glândulas sebáceas. A ocorrência dessa enfermidade deve-se à multiplicação exacerbada do ácaro, sendo geralmente associada a um estado de imunossupressão, mediado pela resposta imune celular (Delayte, 2016).
De acordo com a extensão das lesões, a demodicidose pode ser classificada, semiologicamente, em localizada (DL) ou generalizada (DG). A DL consiste, muitas vezes, em quadros autolimitantes, associados a um satisfatório prognóstico, enquanto a DG representa uma moléstia de maior gravidade, que requer manejo terapêutico prolongado $\mathrm{e}$ laborioso para a obtenção da cura clínica e parasitológica (Mueller, 2004; Delayte, 2016).

Recebido em 28 de novembro de 2016

Aceito em 20 de abril de 2017

E-mail: artur_brilhante@hotmail.com 
Classicamente o tratamento da DG consistia no uso tópico de amitraz, a primeira substância licenciada para o tratamento de tal enfermidade. Recomendam-se banhos com intervalos de sete a 14 dias, durante várias semanas (Mueller, 2004). Com eficácia variando entre 60 e $95 \%$, essa opção terapêutica predispõe a riscos de intoxicação tanto do animal quanto do manuseador, além de apresentar elevada probabilidade de ineficiência devido a diluições e aplicações errôneas (Delayte, 2016).

Posteriormente, as avermectinas e milbemicinas, fármacos endectocidas e pertencentes ao grupo das lactonas macrocíclicas, passaram também a ser empregadas no tratamento da DG, de modo sistêmico (Mueller, 2004). A ivermectina e a moxidectina são as principais representantes da classe terapêutica, apresentando eficácia acima de $85 \%$ quando utilizadas por via oral. No entanto, o tratamento demanda um longo período, que ultrapassa alguns meses, para a obtenção da cura parasitológica (Delayte et al., 2006). Além disso, existem restrições quanto ao uso desses medicamentos em algumas raças e em animais muito jovens (Andrade, 2015; Delayte et al., 2016).

Recentemente, foi lançado, no mercado brasileiro, o fluralaner, um princípio ativo antiparasitário integrante do grupo das isoxazolinas. Com administração por via oral, esse produto apresenta efetividade contra pulgas e carrapatos por um período de 12 semanas. Fourie et al. (2015) demonstraram que esse fármaco também tem ação contra o ácaro $D$. canis. Dessa forma, o fluralaner surge como uma alternativa promissora para o tratamento da DG canina. Apesar de existirem inúmeros relatos coloquiais sobre o tratamento dessa enfermidade com a isoxazolina citada, poucas informações são encontradas na literatura acerca de sua utilização com finalidade acaricida. Diante do exposto, o objetivo do presente trabalho foi relatar o êxito do fluralaner no tratamento da demodicidose canina juvenil generalizada.

\section{CASUÍSTICA}

O primeiro caso se refere a um canino, macho, três meses de idade, sem raça definida, pesando $3,9 \mathrm{~kg}$, o qual foi atendido no Hospital Veterinário da Universidade Federal Rural do Semiárido (Ufersa), situado na cidade de
Mossoró, Rio Grande do Norte, Brasil. O animal possuía o histórico de alterações dermatológicas com tempo evolutivo de um mês. Topograficamente, as lesões cutâneas iniciaramse bilateralmente na região periocular e posteriormente generalizaram-se para as demais áreas anatômicas.

Submeteu-se o animal ao exame físico, por meio do qual se observou rarefação pilosa em região cervical dorsal estendendo-se até a região torácica (Fig. 1), em associação a eritema, pápulas, crostas hemorrágicas e hiperqueratose. Alopecia estava presente na região cervical ventral e na face dorsal dos dígitos dos membros torácicos. $\mathrm{Na}$ região abdominal ventral, foram constatadas pústulas. Havia crostas hemorrágicas em ponte nasal e região mentoniana. Os parâmetros fisiológicos estavam dentro da normalidade e não foram evidenciadas alterações aparentes em outros sistemas. Realizou-se o exame parasitológico do raspado cutâneo (EPRC), no qual foram observados vários espécimes do ácaro D. canis.

O segundo caso foi representado por um canino, fêmea, dois meses de idade, sem raça definida, pesando 4,5kg, também atendido no Hospital Veterinário da Ufersa. $\mathrm{Na}$ anamnese da cadela, relatou-se a presença de lesões cutâneas, com prurido discreto, sendo percebidas havia um mês. As anormalidades dérmicas foram inicialmente detectadas na região cefálica e, posteriormente, distribuíram-se para o restante do tegumento. A genitora e os demais indivíduos pediátricos da mesma ninhada também apresentaram sinais clínicos similares.

$\mathrm{Na}$ avaliação física da paciente, constatou-se alopecia e crostas melicéricas envolvendo por completo a região cefálica, em combinação com hiperqueratose e escamas furfuráceas (Fig. 2). As regiões cervical ventral, costal e abdominal apresentavam rarefação pilosa, escamas furfuráceas e pústulas. Alopecia periocular também estava presente. Não foram evidenciadas anormalidades nos parâmetros fisiológicos, assim como nos outros sistemas orgânicos. Executou-se o EPRC, demonstrando-se a presença de vários exemplares adultos e imaturos do ácaro D. canis.

Assim, ao se estabelecer o diagnóstico de demodicidose, na forma generalizada, foi 


\section{Uso do fluralaner...}

prescrita, para ambos os animais, terapia específica à base de fluralaner em dose única e conforme recomendado em bula pelo fabricante (250mg/animal, Bravecto ${ }^{\circledR}$, MSD Saúde Animal, São Paulo, SP, Brasil), associada ao tratamento adjuvante à base de xampu de peróxido de benzoíla $2,5 \%$ (banhos a cada 72 horas, durante 30 dias $)$ e domperidona $(0,5 \mathrm{mg} / \mathrm{kg}$, a cada 12 horas, durante 60 dias).

Em ambos os casos, observou-se resposta favorável na condição cutânea, com início da repilação ao $10^{\circ}$ dia após a administração do fármaco, tornando-se completa na quarta semana seguida do primeiro e único fornecimento do fluralaner. Não foram constatados efeitos colaterais. Durante o seguimento clínico, adequou-se a dose da domperidona ao peso de cada paciente, que se encontrava em fase expansiva de crescimento.

Para acompanhamento da eficácia da terapia, realizou-se EPRC para investigação do D. canis nos dias 75 e 90 após o início do tratamento, sendo os resultados negativos para os dois caninos. Seguidos 90 dias, ocorria completa ausência de lesões dermatológicas e os animais encontravam-se totalmente repilados (Fig. 1 e 2). Ao fim do tratamento, os animais estavam pesando 14,7 e $13,3 \mathrm{~kg}$, respectivamente.

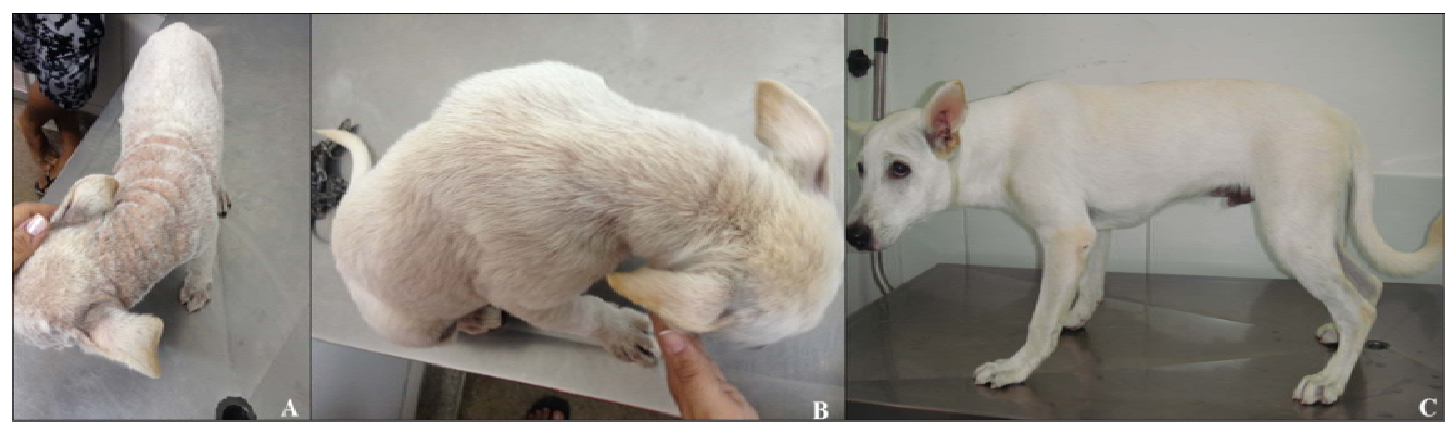

Figura 1. Evolução clínica do primeiro caso (canino, macho, SRD, três meses) no transcorrer do tratamento. A: antes do início da terapia. B: após 15 dias. C: após 90 dias.

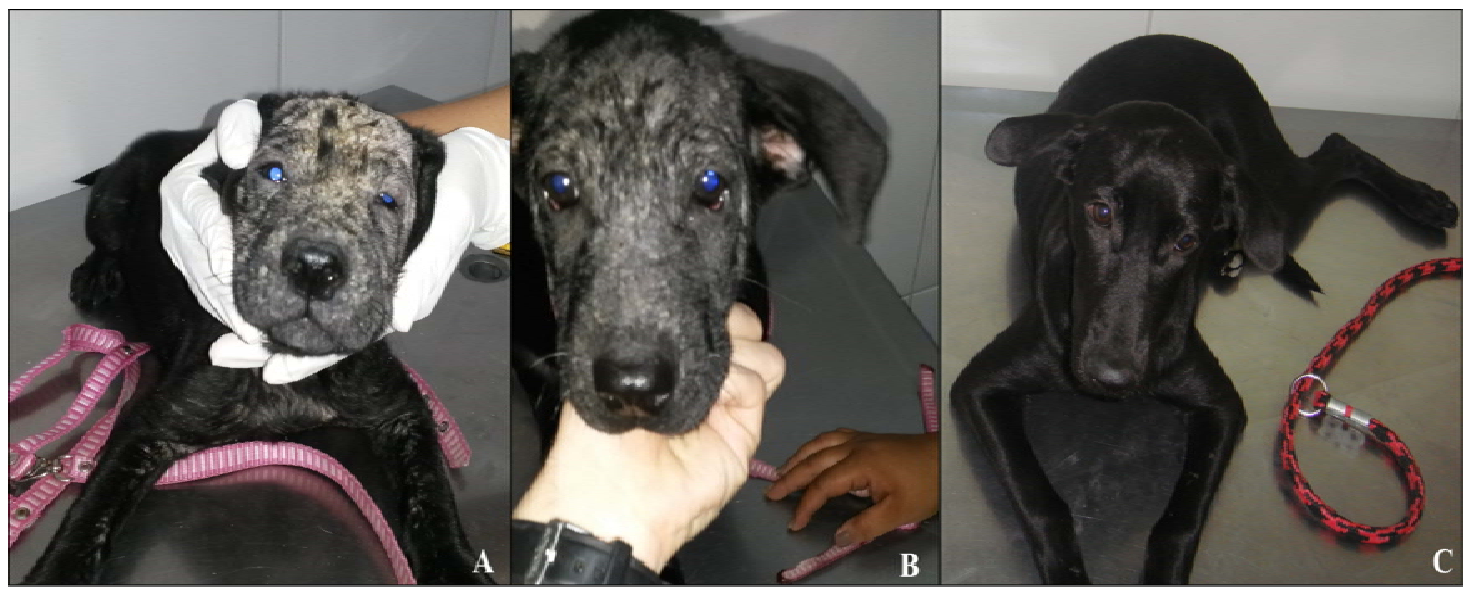

Figura 2. Evolução clínica do segundo caso (canino, fêmea, SRD, dois meses) no transcorrer do tratamento. A: antes do início da terapia. B: após 15 dias. C: após 90 dias.

\section{DISCUSSÃO}

No presente trabalho, demonstrou-se a efetividade do uso do fluralaner no tratamento da demodicidose juvenil generalizada nos cães avaliados. Tal fato foi comprovado pela praticidade e excelente resposta terapêutica ao fármaco, além da inexistência de reações adversas. Os resultados do estudo em discussão corroboraram os encontrados por Fourie et al. (2015), que utilizaram o fluralaner como terapia única, na dose de $25 \mathrm{mg} / \mathrm{kg}$, em oito cães com 
DG, e observaram uma redução no número de ácaros obtidos no EPRC de $99,8 \%$ no dia 28 e de $100 \%$ nos dias 58 e 84 após a administração do medicamento. Esse tratamento demonstrou resultados superiores em comparação ao outro grupo testado, no qual foi utilizada a associação de moxidectina e imidacloprida por via tópica. $\mathrm{O}$ ganho de peso dos canídeos evidenciados no presente trabalho não influenciou o efeito da dose do fluralaner ao longo do período de tratamento.

O fluralaner pertence a um grupo de ectoparasiticidas, denominados isoxazolinas, e apresenta atividade contra o ácido $\gamma$ aminobutírico e os canais de cloro, ativados por glutamato e com seletividade significativamente maior pelos neurônios dos artrópodes em detrimento dos neurônios dos hospedeiros mamíferos (Ozoe et al., 2010). Esse fármaco tem ação inseticida, a qual combate pulgas e carrapatos, além de ação acaricida descoberta recentemente (Fourie et al., 2015). É uma substância que apresenta uma adequada segurança, pois não demonstra potencial de intoxicação mesmo quando administrada em quantidade cinco vezes acima da dose máxima terapêutica recomendada para cães (Walther et al., 2014a). Essas características encorajaram a utilização do fluralaner como uma opção prática e resguardada para o tratamento da DG nos indivíduos explicitados.

Outra vantagem do uso do fluralaner é a possibilidade do emprego seguramente em cães a partir de oito semanas de idade. As lactonas macrocíclicas, por exemplo, apresentam restrição quanto à administração a cães muito jovens, pois estes ainda possuem a barreira hematoencefálica imatura, o que os torna altamente susceptíveis a intoxicações de ordem neurológica. A idade mínima segura para administração da ivermectina, por exemplo, varia de acordo com o autor, não sendo recomendada em animais com menos de seis meses de idade (Andrade, 2015). Dessa forma, o tratamento com a ivermectina nos animais em discussão poderia conduzir a malefícios à sanidade, com risco elevado de efeitos colaterais, o que desestimulou a sua utilização.

No que concerne às lactonas macrocíclicas, principalmente a ivermectina, ainda existe outro inconveniente, que é a contraindicação para determinadas raças, como os Collies, Pastores Australianos, Old English Sheepdog, Pastores de Shetland e em exemplares provenientes do cruzamento de tais raças (Andrade, 2015). Nesses animais, devido a uma mutação no gene autossômico recessivo MDR1, há uma produção de glicoproteínas $\mathrm{P}$ defeituosas, o que permite que o medicamento ultrapasse a barreira hematoencefálica, consequentemente, graves repercussões sistêmicas, incluindo o óbito do paciente (Andrade, 2015; Delayte, 2016). Isso não seria um problema relacionado ao fluralaner, já que foi demonstrada ausência de toxicidade quando administrado três vezes acima da dose máxima recomendada em cães da raça Collie, sabidamente portadores da mutação do gene MDR1 (Walther et al., 2014b).

O uso do fluralaner demonstra uma grande praticidade, pois, com apenas uma administração, é possível ter o controle da DG por, no mínimo, 12 semanas. Isso é extremamente vantajoso em relação às lactonas macrocíclicas, que demandam administrações que podem ter frequência diária e por longos períodos para se alcançar a cura parasitológica do animal, e também no que se refere ao uso do amitraz, que requer banhos semanais (Mueller, 2004; Delayte, 2006). Outras moléculas do grupo das isoxazolinas, como o sarolaner e o afoxolaner, também exibiram boa eficácia contra o $D$. canis, o que levou a reduções na quantidade do ácaro de $99,8 \%$ e $99,2 \%$, respectivamente, em um mês após a administração (Beugnet et al., 2016; Six et al., 2016).

Para ambos os casos relatados, a domperidona foi utilizada com a finalidade imunoestimulante. Esse fármaco, comumente empregado por sua ação procinética, é um antagonista dos receptores de dopamina D2. Em altas doses, conforme foi realizado nos animais analisados, a domperidona acarreta o aumento da concentração sérica de prolactina, que, além de estimular a produção de leite em mamíferos, atua como uma citocina próinflamatória, com papel central na resposta imune. Assim, há uma ativação de linfócitos $\mathrm{T}$ que, secundariamente estimulam os macrófagos e, como consequência, beneficiam a resposta imune celular do animal (Hinterberger-Fischer, 2000). A escolha do xampu de peróxido de benzoíla a $2,5 \%$ na terapia adjuvante dos caninos em discussão foi baseada nas suas propriedades 
antibacteriana, antisseborreica e antipruriginosa. Além disso, esse princípio ativo tem um efeito de lavagem no interior dos folículos pilosos, o que auxilia na expulsão do ácaro, na redução da inflamação e na melhora do estado cutâneo geral (Mueller, 2004).

De modo coloquial, é conhecido o uso rotineiro do fluralaner na terapia da demodicidose em cães por inúmeros médicos veterinários. No entanto, ainda são bastante escassos trabalhos abordando essa temática na literatura. Nesse sentido, ao conhecimento dos autores, este estudo provavelmente representa um dos primeiros a demonstrar a efetividade do fluralaner no tratamento da demodicidose juvenil generalizada canina. Porém, trabalhos futuros ainda são necessários para se definir um protocolo de tratamento com esse fármaco, incluindo padronização de dose, frequência de administração e seguimento para alta parasitológica e clínica.

\section{CONCLUSÃO}

O fluralaner se mostrou altamente eficaz, prático e resguardado no tratamento da demodicidose juvenil generalizada canina. Dessa forma, recomenda-se a inclusão do fluralaner nos protocolos terapêuticos para a demodicidose canina, essencialmente nos pacientes pediátricos e com a forma disseminada da enfermidade cutânea.

\section{REFERÊNCIAS}

ANDRADE, S.F. Intoxicação por amitraz, avermectinas e milbemicinas. In: JERICÓ, M.M.; ANDRADE-NETO, J.P.; KOGIKA, M.M. Tratado de medicina interna de cães $e$ gatos. Rio de Janeiro: Roca, 2015. p.627-630.

BEUGNET, F.; HALOS, L.; LARSEN, D. et al. Efficacy of oral afoxolaner for the treatment of canine generalised demodicosis. Parasite, v.23, p.1-8, 2016.

DELAYTE, E.H. Demodicidose canina. In: LARSSON, C.E.; LUCAS, R. Tratado de medicina externa: dermatologia veterinária. São Caetano do Sul: Interbook, 2016. 853p.
DELAYTE, E.H.; OTSUKA, M.; LARSSON, C.E. et al. Eficácia das lactonas macrocíclicas sistêmicas (ivermectina e moxidectina) na terapia da demodicidose canina generalizada. Arq. Bras. Med. Vet. Zootec., v.58, p.31-38, 2006.

FOURIE, J.J.; LIEBENBERG, J.E.; HORAK, I.G. et al. Efficacy of orally administered fluralaner (Bravecto ${ }^{\mathrm{TM}}$ ) or topically applied imidacloprid/moxidectin (Advocate ${ }^{\circledR}$ ) against generalized demodicosis in dogs. Parasit. Vectors, v.187, p.1-7, 2015.

HINTERBERGER-FISCHER, M. Prolactin as pro-inflammatory cytokine - considerations on consolidated immunotherapy after high dosage therapy. Acta Med. Austriaca. Suppl., v.52, p.1620, 2000.

MUELLER, R.S. Treatment protocols for demodicosis: an evidence-based review. Vet. Dermatol., v.15, p.75-89, 2004.

OZOE, Y.; ASAHI, M.; OZOE, F. et al. The antiparasitic isoxazoline A1443 is a potent blocker of insect ligand-gated chloride channels. Biochem. Biophys. Res. Commun., v.391, p.744749, 2010.

SIX, R.H.; BECSKEI, C.; MAZALESKI, M.M. et al. Efficacy of sarolaner, a novel oral isoxazoline, against two common mite infestations in dogs: Demodex spp. and Otodectes cynotis. Vet. Parasitol., v.222, p.6266, 2016.

WALTHER, F.M.; ALLAN, M.J.; ROEPKE, R.K.A. et al. Safety of fluralaner chewable tablets (Bravecto ${ }^{\mathrm{TM}}$ ), a novel systemic antiparasitic drug, in dogs after oral administration. Parasit. Vectors, v.87, p.1-7, 2014a.

WALTHER, F.M.; PAUL, A.J.; ALLAN, M.J. et al. Safety of fluralaner, a novel systemic antiparasitic drug, in MDR1(-/-) Collies after oral administration. Parasit Vectors, v.86, p.1-7, 2014b. 